\title{
Osteosarcoma of the Maxilla Masquerading as Maxillary Mucocele on CT Scan: A Case Report
}

\author{
1Satyawati Mohindra, ${ }^{2}$ Amanjit K Bal, 33agvir Yadav
}

${ }^{1}$ Assistant Professor, Department of Otolaryngology and Head and Neck Surgery, Postgraduate Institute of Medical Education and Research Chandigarh, India

${ }^{2}$ Assistant Professor, Department of Histopathology, Postgraduate Institute of Medical Education and Research, Chandigarh India

${ }^{3}$ Senior Resident, Department of Otolaryngology and Head and Neck Surgery, Postgraduate Institute of Medical Education and Research, Chandigarh, India

Correspondence: Satyawati Mohindra, Assistant Professor, Department of Otolaryngology, PGIMER, Sector-12 Chandigarh-160012, India, Phone: 91-172-2756765, Fax: 91-172-2744401, 2747837, e-mail: satyamohindra@gmail.com mohindrasatyawati@yahoo.com

\begin{abstract}
Purpose: The authors intend to present a case of osteosarcoma of the maxilla which presented like a mucocele, a previously unreported phenomenon.

Patients and methods: Clinical features, radiology, histopathological findings and endoscopically managed osteosarcoma of the maxilla are presented. Diagnostic difficulties and previously reported diagnostic dilemmas related to osteosarcomas of the maxillary sinus are discussed.

Results: The patient has been on regular follow-up for the past 10 months, and is free from any local or systemic disease.

Conclusion: Though osteosarcoma of the maxilla is a rare tumor about $6.5 \%$ of all osteosarcomas ${ }^{1}$, patients tend to be in the late-third to mid-fourth decades of life, a high index of suspicion and aggressive management can reduce the morbidity that goes with the management of this condition.
\end{abstract}

Keywords: Osteosarcoma, maxilla, mucocele.

\section{INTRODUCTION}

Osteosarcoma of the jaw bone is comparatively rare and accounts for about $6.5 \%$ of all osteosarcomas. Patients with osteosarcoma in this region tend to be in the late third to mid fourth decades of life. The median age has been reported as 31 years in one of the series. ${ }^{1}$ Clinically the tumor may be central or peripheral and histologically can be divided into three subtypes: Osteoblastic, fibroblastic, and chondroblastic. $^{2}$

We report a case of osteosarcoma of the maxilla in a 12 year boy who presented to us with proptosis, and diplopia of eight months duration, which was gradually progressive and followed trauma to cheek one month prior to the complaints.

\section{CASE REPORT}

A 12 years old boy presented to us with upward and lateral protrusion of left eye for the past eight months which was insidious and gradually progressive. There was associated watering of left eye, diplopia in medial and inferior gaze, swelling of the left cheek and bilateral nasal obstruction with associated watery nasal discharge. There was no history of epistaxis and loosening of teeth. There was a history of injury to left cheek with a cricket ball one month prior to his complaints. Anterior rhinoscopy showed deviated nasal septum to right side and a smooth bulge in the region of middle meatus which was firm on probing, sensitive to touch and not bleeding. Ophthalmological examination was unremarkable except for proptosis (Fig. 1). CECT of Nose and PNS showed a homogenous soft tissue density occupying left maxillary sinus, indenting the orbit with areas of bony resorption and thickening suggestive of a mucocele (Fig. 2). Patient was taken up for endoscopic marsupialization under general anesthesia. After entering the firm swelling which was seen in the middle meatus there was a friable bleeding mass which was partially debrided and sent for histopathological examination. Due to clinico-radiological discordance, MRI was done, which showed a hyperintense lesion on T1 (Fig. 3). The tumor was excised completely 


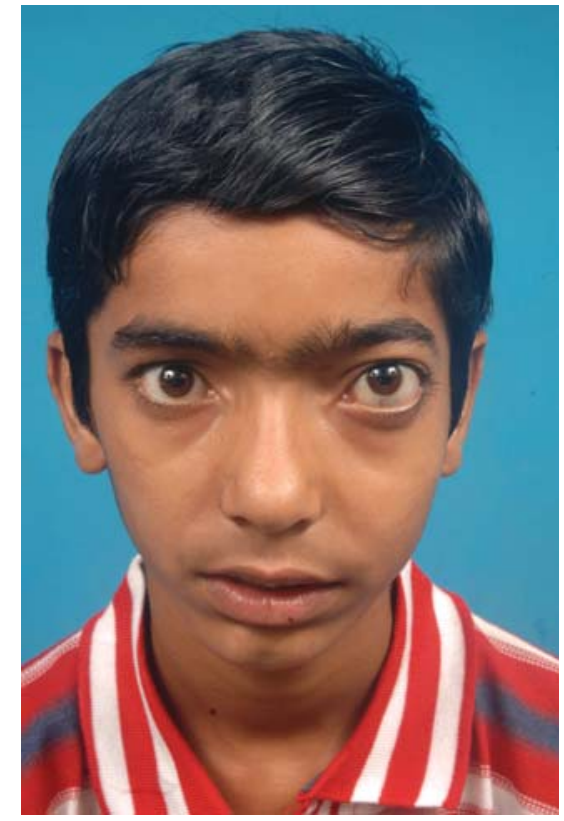

Figure 1: Clinical photograph of the patient showing nonaxial proptosis

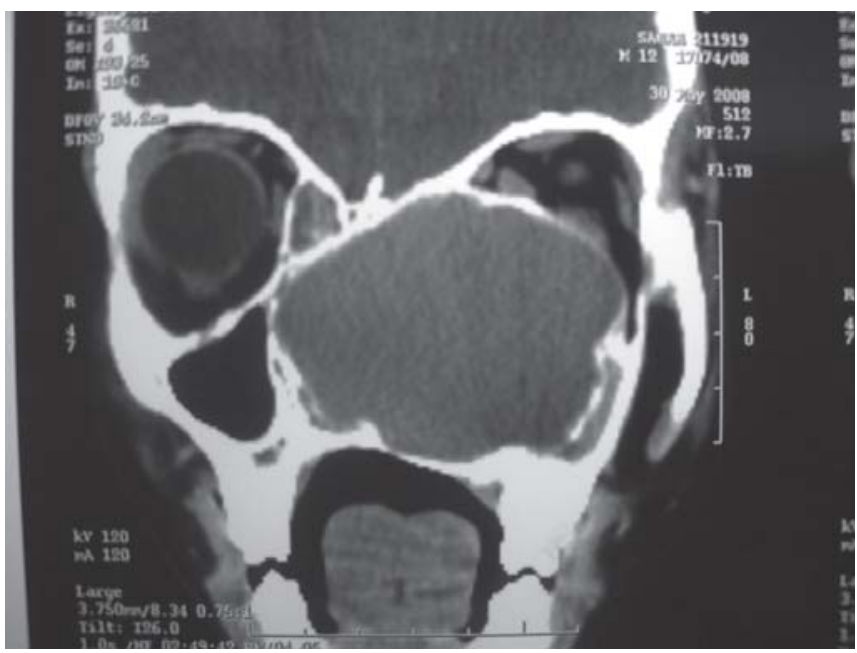

Figure 2: Computed tomography scan, coronal section showing a homogenous soft tissue density occupying left maxillary sinus, indenting the orbit with areas of bony resorption and thickening suggestive of a mucocele

using an endoscope which was confirmed on postoperative scan (Fig. 4). The histopathological examination was reported as mesenchymal chondrosarcoma, so a definitive endoscopic excision was done. Postoperative scan shows complete excision. Final histopathological report was osteogenic sarcoma (Figs 5 and 6) and showed a cellular tumor displayed in multiple fragments and arranged in sheets, whorls as well as lobules of spindle shaped tumor cells in a myxoid background with huge osteoid formation. Tumor cells were mildly pleomorphic, round to spindle shaped with

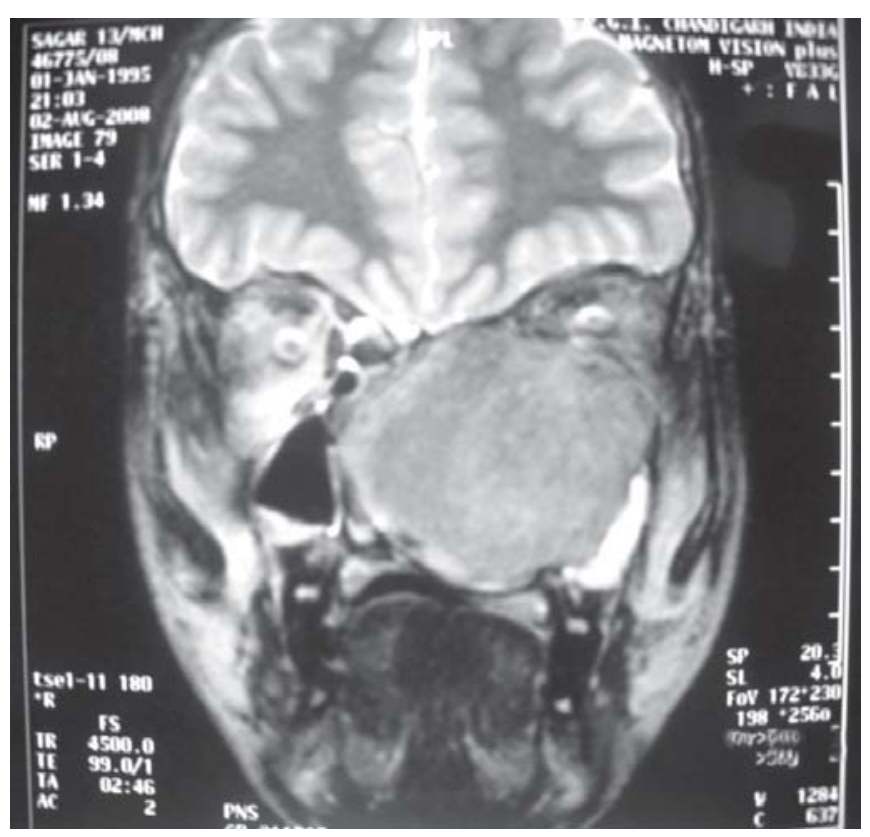

Figure 3: MRI was done, which showed a hyperintense lesion on T1 weighted sequence

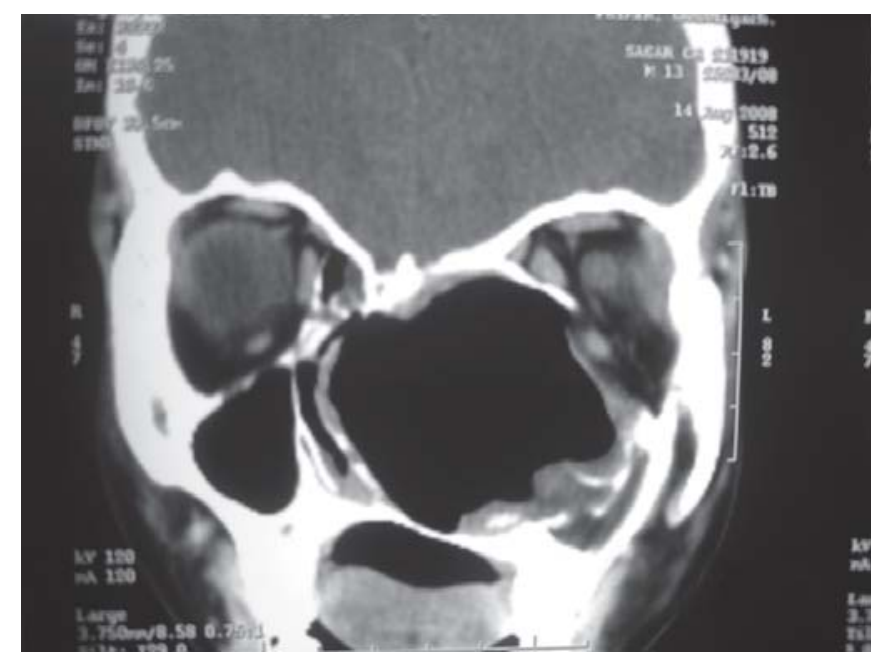

Figure 4: Postoperative computed tomography scans demonstrating complete excision of the tumor

calcification and high mitotic activity. Focally giant cell reaction, lymphoid aggregates and focally intact respiratory lining epithelium were also seen. Postoperatively the patient received six cycles of cisplatinum based chemotherapy and radical radiotherapy. At 10 months follow-up he is free from any local or systemic disease. Postoperative whole body PET (positron emission tomography) showed physiological uptake of the contrast, with no evidence of local recurrence or systemic metastasis (Fig. 7). 


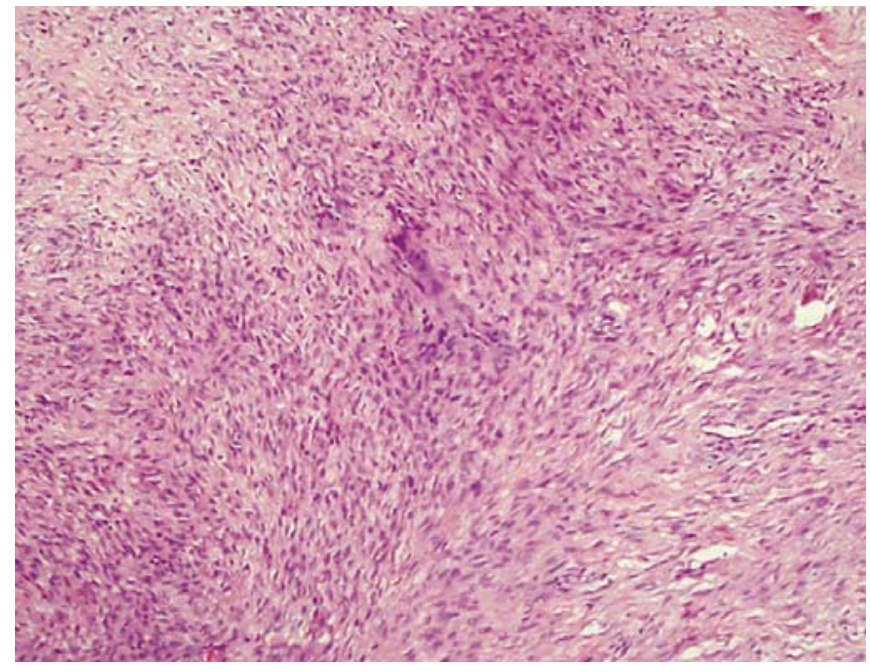

Figure 5: Photomicrograph showing cellular tumor with spindle shaped cells arranged in fascicles and having moderate nuclear pleomorphism and scanty cytoplasm (hematoxylin and eosin, X100)

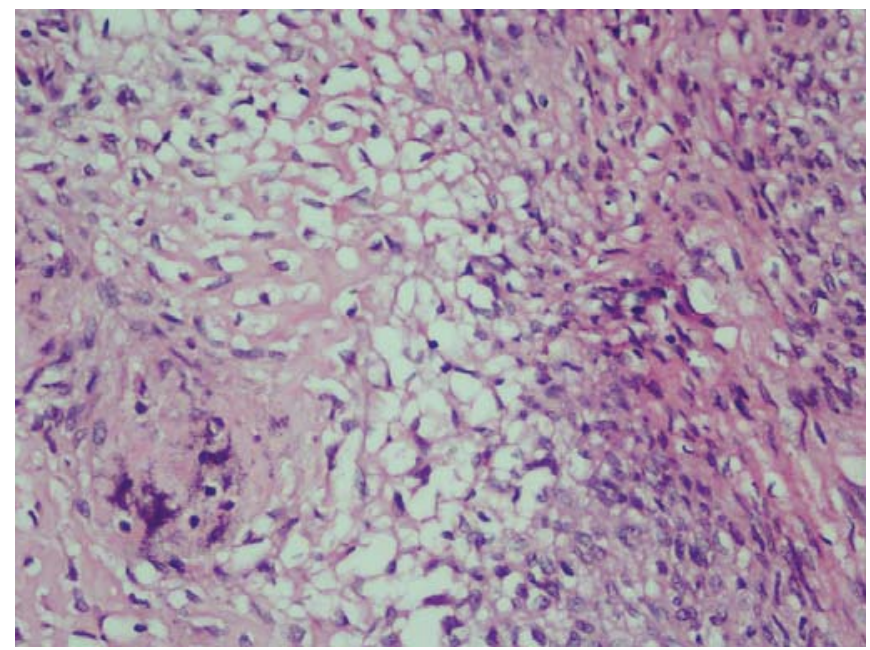

Figure 6: Photomicrograph showing spindle shaped tumor cells laying down eosinophilic osteoid with superimposed calcium deposition (hematoxylin and eosin, X200)

\section{DISCUSSION}

Osteosarcomas of the jaws account for about $6.5 \%$ of reported neoplasms of this type. Patients with osteosarcoma in this region tend to be in the late-third to mid-fourth decades of life. We have come across a single report in a four and half year's boy. ${ }^{4}$ This is probably the second report in a young boy, 12 years of age. ${ }^{3}$ The incidence being low, case reports are an opportunity to discuss issues of clinical and diagnostic significance.

The clinical features are completely different from the patients reported in literature. ${ }^{5}$ Our patient presented with visual symptoms of proptosis, diplopia and epiphora. The tumor probably originated from the superior-medial part of

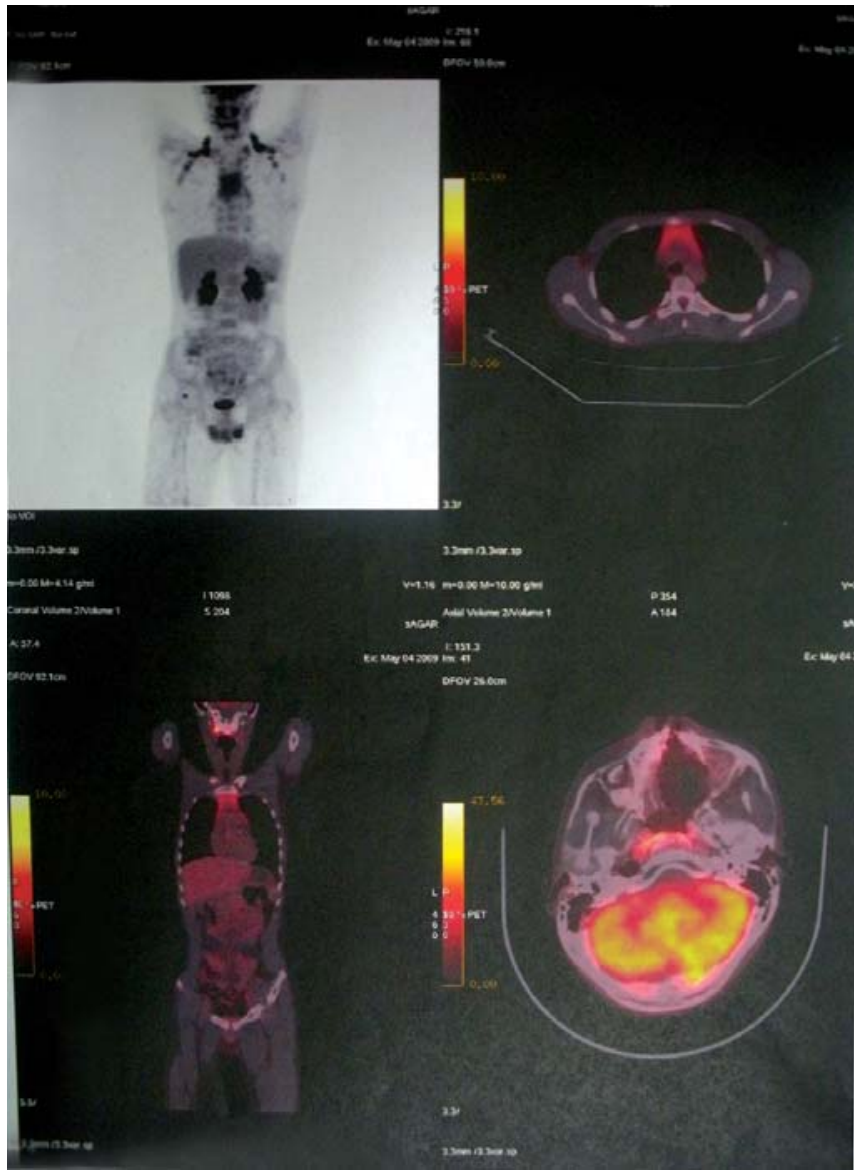

Figure 7: Whole body PET (positron emission tomography) showing physiological uptake of the contrast and no evidence of local recurrence or systemic metastasis

the maxilla in close proximity to the orbit. There is an associated history of trauma which probably drew attention to the already present subtle symptoms. Associated hemorrhage into the already present maxillary mass can be another explanation. This has compelled the patient to seek medical advice earlier which otherwise he would have ignored.

Computed tomography showed well-defined homogeneous soft tissue density causing expansile remodelling of the adjoining bones of the maxilla and ethmoids. A diagnosis of giant mucocele of maxillary sinus was entertained. MRI revealed a hyperintense lesion on both $\mathrm{T} 1$ and $\mathrm{T} 2$ weighted sequences thereby indicating the presence of a soft tissue tumor and not just retained secretion like that of a mucocele. There was no osteogenesis seen on CT scan in the present patient. A correlation between osteogenesis on CT scan and prognosis has been seen in the past. ${ }^{6}$

The initial histopathology was reported as mesenchymal chondrosarcoma which was later on reported to be an osteogenic sarcoma. The initial report was based on biopsy 
and the final on the surgically excised specimen. It is possible that the osteoid formation is missed on smaller tissue specimen as that of a biopsy and there may be focal islands of cartilage formation which can be interpreted as chondrosarcoma.

Diagnostic difficulties are common in osteosarcomas of the jaw. It has previously been misdiagnosed clinically, radiographically, and histopathologically as fibrous dyspalsia, ${ }^{7}$ chondrosarcoma, ${ }^{8}$ Ewing's sarcoma, ${ }^{9}$ bone metastasis ${ }^{10,11}$ and osteomyelitis. ${ }^{12}$ We are adding one more differential diagnosis of mucocele to this list.

The present case highlights many unusual features not commonly seen in patients with osteosarcoma of the maxilla. The age group of the patient (12 years) has only once been reported in the past, ${ }^{4}$ the clinical presentation (proptosis and epiphora), the radiological picture suggesting a diagnosis of mucocele has not been reported in the past. Our patient represents the other end of the spectrum (early presentation) which enabled us to completely excise the tumor endoscopically without sacrificing the ipsilateral eye and also avoiding any cosmetic deformity as that seen after total maxillectomy. To this we added an aggressive course of chemotherapy and radiotherapy. He is completely free of any local or systemic disease at 10 months of follow-up.

Osteosarcomas of the maxilla are reported to have a better prognosis than that of the long bones ${ }^{13}$ but a high index of suspicion, aggressive treatment and a very strict and regular follow-up can go a long way in improving the prognosis further.

\section{REFERENCES}

1. Doval DC, Kumar RV, Kannan V, Sabitha KS, Misra S, et al. Osteosarcoma of the jaw bones. Br J Oral Maxillofac Surg 1997;35(5):357.
2. Frei C, Bornstein MM, Stauffer E, Iizuka T, Buser D. Osteosarcoma of the maxilla and the maxillary sinus: A case report. Quintessence Int 2004;35(3):228.

3. Rinaggio J, Kewitt GF, McGuff HS. Epithelioid osteosarcoma presenting as a rapidly expanding maxillary mass. Head Neck 2007;29(7):705.

4. Kaveri H, Rekha K, Punnya VA. Epithelioid osteosarcoma of the maxilla: Report of an unusual case. Br J Oral Maxillofac Surg 2008;31:143.

5. August M, Magennis P, Dewitt D. Osteogenic sarcoma of the jaws: Factors influencing prognosis. Int J Oral Maxillofac Surg 1997;26(3):198.

6. Nakayama E, Sugiura K, Kobayashi I, Oobu K, Ishibashi H, et al. The association between the computed tomography findings, histologic features, and outcome of osteosarcoma of the jaw. J Oral Maxillofac Surg 2005;63(3):311.

7. Bennet JH, Thomas G, Evans AW, Speight PM. Osteosarcoma of the jaw: A 30 year's retrospective review. Oral surg oral med oral pathol oral radiol enod 2000;90(3):323.

8. Saini R, Abd Razak NH, Ab Rehman S, Samsudin AR. Chondrosarcoma of the mandible: A case report. J Can Dent Assoc 2007;73(2):175.

9. Gorospe L, Fernandez Gill-MA, Garcia-raya P, Royo A, LopezBaria F, et al. Ewing's Sdarcoma of the mandible: Radiological features with emphasis on magnetic resonance appearance. Oral surg oral med oral pathol oral radiol enod 2001;91(6):728.

10. Raubenheimer EJ, Noffke CE. Pathogenesis of bone metastasis: A review. J Oral Med 2006;35(3):129.

11. Ottomeni N, Khatab M. Metastatic neuroblastoma to the mandible in a three year old boy: A case report. Med oral Patol oral Cir buccal 2007;12(3):E201.

12. Petrikowski CJ, Pharaoh MJ, Lee L Grace MG. Radiological differentiation of the osteosarcoma, osteomyelitis and fibrous dysplasia of the jaw. Oral surg oral med oral pathol oral radiol enod 1995;80(6):744.

13. Li J, He RG. (Osteosarcoma of maxillofacial area: A clinicopathological study of 61 cases) Zhonghua Kou Qiang Yi Xue Za Zhi 2003;38(6):444. 